\title{
In situ foundation improvement for upstream raising of embankments using dried tailings
}

\author{
D.D. Smirk Red Earth Engineering Pty Ltd, Australia \\ S. Jackson Red Earth Engineering Pty Ltd, Australia
}

\begin{abstract}
The use of upstream construction methods on tailings dams is a common method of increasing the capacity of an earthen tailings dam. However, as this technique involves construction over existing tailings deposits, foundation strength is critical to ensure that the long-term integrity and stability of the wall can be achieved for single or multiple upstream raising campaigns.

For low-strength tailings the conventional approach is to import materials such as rock fill for placement as a bridging layer in the construction area. This proven approach will successfully deliver the required foundation strength improvement. However, suitable rock fill is normally a premium product and hence provides this solution at a high capital cost.

Recently, the authors have completed investigations into processes to improve the foundation strengths at several tailings dams within the alumina industry. The fundamental approach has been to identify tailings dewatering processes that can be applied to alumina tailings (bauxite residue) such that equivalent foundation strengths can be developed in realistic timeframes.

Investigations have concentrated around developing techniques using the MudMaster (twin archimedes screw tractor or amphirol) in combination with conventional earthmoving equipment (swamp dozers/ excavators) to accelerate the dewatering process. These techniques are usually incorporated into the operations of the tailings dam and hence these improvements form part of normal operating costs. Dried tailings from the operational (active) areas can then be used to construct part of the upstream raise (usually zoned within the embankment cross section).

Although the techniques employed need to be tailored to an operating site (based on climatic conditions, production rates etc.) the fundamental principles remain consistent. Foundation strength improvements from $<5 \mathrm{kPa}$ to well above $30 \mathrm{kPa}$ within 90 days have been achieved with net capital savings over A\$ 1 million per site compared to convention construction methods using dumped rock and imported materials. After success at several locations, the authors have developed a simplified foundation improvement method that can be applied almost anywhere.
\end{abstract}

This paper will detail the general dewatering techniques developed, the foundation strength improvements achieved and the costs to achieve this improvement.

\section{Introduction}

Upstream construction on tailings dams is critically dependent on the strength of the underlying tailings. In situations where there is minimal strength in the existing tailings, the conventional approach is to use rock fill (or similar) to develop the required foundation strength. This approach, while conservative, does come at a high capital cost and can be avoided or minimised by improving the strength of the in situ tailings.

In tailings that develop high strength at high density, another way of achieving improvements in the foundation strength is through local in situ dewatering. A conventional approach to in situ dewatering requires the application of wick drains (or other vertical drainage) to relieve entrained tailings liquors but this is also cost prohibitive over large areas and restrictive in terms of access and impact on operations. Reliance on drainage systems also depends on the permeability of the tailings and selected geotextiles, which are inherently susceptible to clogging with a high proportion of super-fines associated with tailings. What is 
required is a cost effective means of rehandling and dewatering tailings that can be safely managed as an operational cost and within a realistic timeframe.

The application of mud farming practices to improve tailings management has been documented previously (Cooling, 2006; Power et al., 2009). The benefits of mud farming can be summarised as:

- a means of reducing the overall tailings disposal footprint

- achieving a significantly higher overall density in the deposit

- achieving a high overall strength in the tailings deposit

- reducing the potential for surface dust generation.

Mud farming practices have evolved from the application of swamp bulldozers to advanced Archimedes screw tractors or amphirols (MudMasters). The primary benefits of these machines are to:

- permit a deep layer of tailings to be safely managed

- reduce the risk of re-pulping of the tailings layer during seasonal wet seasons

- lower overall operating unit cost relative to bulldozers.

The MudMaster is shown in Figure 1.

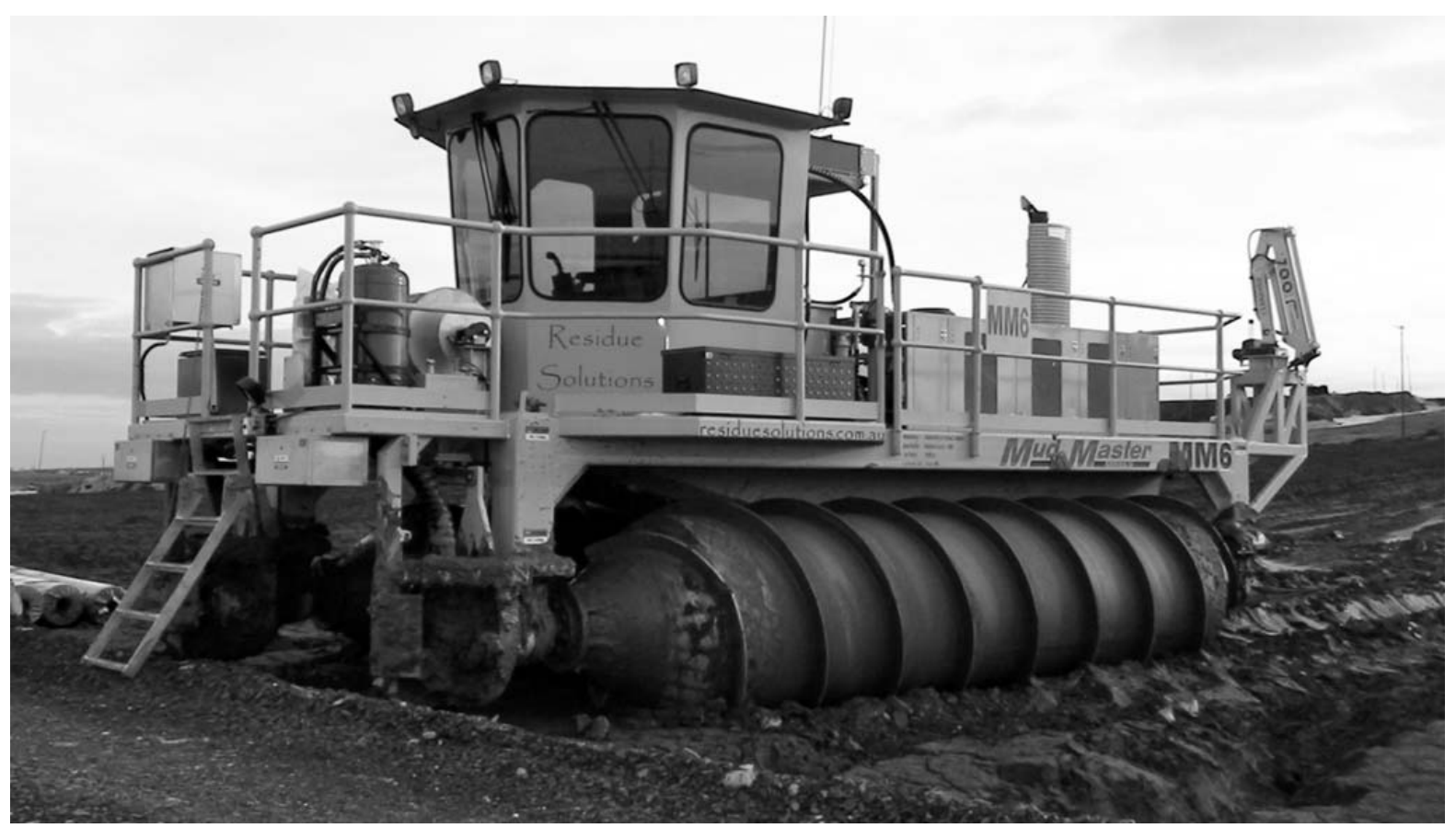

Figure 1 MudMaster Series IV (Residue Solutions Pty Ltd)

As part of recent investigations at a range of sites, this capability has been modified to safely and costeffectively dewater deep poorly-consolidated tailings for the purposes of constructing a foundation zone suitable for upstream construction.

Whilst this paper focuses on the strength improvement of existing tailings via in situ dewatering, it is recognised that a combination of techniques may be required to achieve suitable density and strength in deep (i.e. greater than $8 \mathrm{~m}$ ) deposits of tailings with excess pore pressure. The authors discuss several alternative approaches that should be considered when approaching ground improvement of tailings. 


\section{Methodology}

In the alumina industry, MudMasters are currently used to manage approximately $25 \%$ of all bauxite residue generated globally. With the technology in widespread use, the authors have sought to develop a common approach to foundation improvements.

The use of MudMasters is normally associated with the practice of mud farming where tailings are placed in discrete high-density layers ( $>40 \%$ solids $\mathrm{w} / \mathrm{w}$ ) up to $1,000 \mathrm{~mm}$ deep and routinely ploughed to enhance dewatering via consolidation and evaporative losses. Depending on the regional climate, the density of a single layer of tailings can normally be increased to $70 \%$ solids in a 30-90 day timeframe.

The authors have applied sound geotechnical engineering practice with these dewatering tools (and methods) to maximise the ground improvement possible within the foundation for upstream raising. This approach can result in significant capital savings (when compared to conventional methods) however requires increased geotechnical investigation and ongoing monitoring to accurately define the depth and strength of tailings before, during and after construction.

\section{$2.1 \quad$ Goals}

The goals of the foundation improvement programme are to provide:

- a safe means of in situ dewatering using suitable equipment

- a dewatering process that can occur within a defined period and modelled in advance

- ground improvement that meets geotechnical requirements

- general guidelines for application for any site but tailored to accommodate site-specific needs

- a cost-effective foundation improvement option that could also be completed as a routine operational practice and cost

- minimal impact on operational areas (upstream raising can occur on operational dams).

\subsection{Development plan}

As with any development programme an execution plan of events is required to enable resource planning, timing and a basis for assessing on-going monitoring. The development programme will be defined by the size of the tailings area requiring foundation improvement activities and the time for this improvement to be achieved. Although every site and foundation improvement programme will be different, it is possible to develop a generalised framework approach. This approach encompasses the following phases to determine the:

- geotechnical targets for foundation improvement

- geotechnical design of the upstream raise to satisfy stability and settlement criteria

- timeline to achieve this improvement

- modelled prediction of improvement performance.

Each phase is then tailored to site specific parameters and requirements.

Regardless of the techniques employed, site geotechnical engineering support is required to define the foundation strength requirements and the depth over which this is to be achieved. Nominally this is defined as a depth of tailings that must record shear strength in excess of a nominated value, subject to stability analysis.

The actual target is dependent on the properties of the tailings, the location, height and geometry of the proposed upstream construction. Ground improvement using MudMasters is typically limited to a depth of $2 \mathrm{~m}$, giving a $2 \mathrm{~m}$ thick relatively stiff foundation platform for subsequent upstream construction (typically $>30 \mathrm{kPa}$ ). Subsequent layers of tailings can be placed within the upstream construction zone and dried using the normal operational mud-farming techniques. 
It is noted that, from industry experience, the height of upstream raise "stages" in typically limited to $2-5 \mathrm{~m}$. The height of the raise is normally limited to minimise the impact on operational sites and to minimise the encroachment into the existing operations mud-farming areas (active mud-farming area is premium realestate at most sites). The global (and local) slope stability challenges associated with a $5 \mathrm{~m}$ raise are (in most cases) overcome by the construction of a $2 \mathrm{~m}$ thick foundation.

If slope stability concerns require further stabilisation measures (for critical sections along the walls), the prepared foundation platform allows access for:

- excavation of deeper dewatering 'slots' using excavators, then backfilling with rock

- placement of high strength geotextile/geogrid/rock layers to intercept failure surfaces in critical areas identified by geotechnical design.

Seasonal restrictions normally require any foundation improvement and upstream construction to occur within the dry season. Typically this encompasses a six month period. To accommodate the upstream construction phase of the programme this normally means that any foundation improvement works must be completed to target specifications within three months (90 days).

It is possible to model the maximum rate of dewatering by examining liquid losses from tailings due to climate variables and also the consolidation properties of the tailings. The size of the upstream construction effort will define the area of the foundation footprint that will require dewatering and the required strength improvement. The authors use a specifically developed planning and scheduling package (MUDFARM ${ }^{\mathrm{TM}}$ developed by Residue Solutions Pty Ltd) to define the usage of MudMasters over the foundation improvement area to achieve the required density.

Prior to modelling it is necessary to determine how a tailings layer will release its entrained liquor. Using conventional theory this occurs through:

- deep drainage and surface decantation of bleed waters in response to consolidation

- classical three stage soil drying evaporative processes.

In situations where there is limited drainage available, due to elevated water levels, the net losses are largely determined by climate. The relative impact of the elevated water levels can only be determined through observation. As such activities need to be modified to meet site-specific requirements.

With this information entered into MUDFARM ${ }^{\mathrm{TM}}$ it is possible to forecast predicted tailings surface levels.

\subsection{Sequence of events}

For this approach to be effective disposal operations must be discontinued in the foundation improvement area. The tailings dam being raised can continue to be used for mud farming activities usually by designing an alternative inboard discharge layout (or alternative discharge location) to sustain the operation.

\subsubsection{General layout}

The generalised layout of operations needs to reflect the capabilities of the MudMaster. This includes providing a ready means of recovery if a machine and/or operator require rescue (a fundamental Health and Safety requirement for the operation of amphirols). In general, the operations of the MudMaster are best suited to long ploughing traverses that minimise multiple workings over low-density tailings. This reduces the risk of local liquefaction of the tailings and reduced traction. As such traverses should be angled at $45^{\circ}$ to the perimeter wall with the vehicle tethered to enable rapid recovery if required. The length of the traverse should not exceed $50 \mathrm{~m}$ thereby limiting the maximum rescue distance to $35 \mathrm{~m}$ from the perimeter wall.

In situations where the footprint of the proposed foundation exceeds $35 \mathrm{~m}$ then a staged approach to foundation improvement is required where the first section (closest to the perimeter wall) must be completed to the desired targets before moving operations in-board and repeating the process.

The general arrangement of a foundation improvement area is shown in Figure 2. 


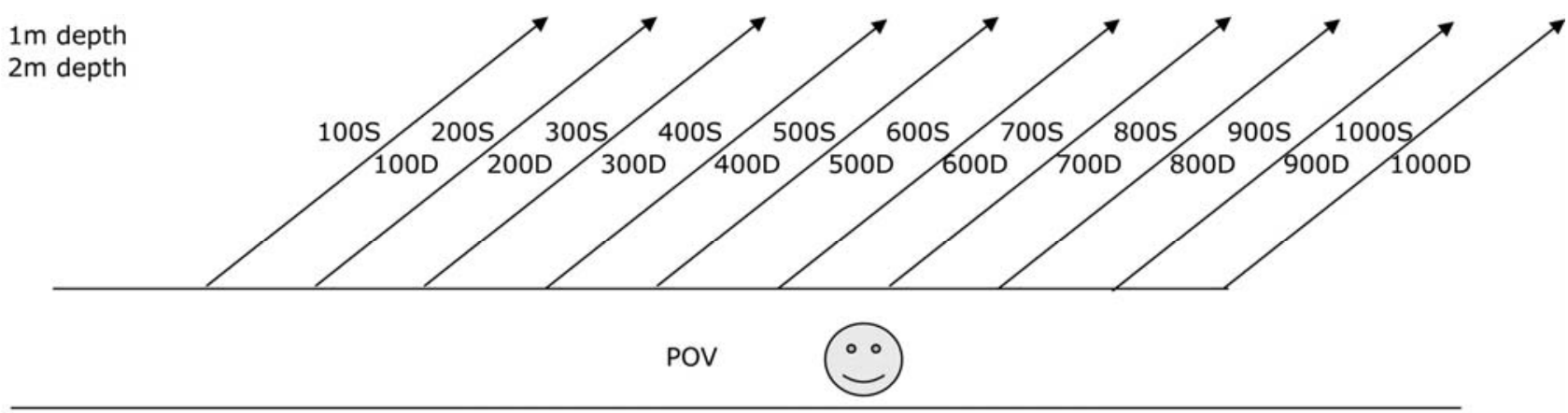

Wall

\section{Figure 2 Truncated Herringbone surface ploughing pattern}

Any recovery operation will commence from the adjacent embankment (as shown in Figure 2) and align the direction of the herringbone pattern towards the lowest point within the dam to improve drainage. If the tailings density prevents controlled steerage (due to insufficient traction) an excavator should be positioned at the starting point of the ploughing transect and tethered to the MudMaster.

\section{Step 1 - Day 1}

Commence scrolling at a $45^{\circ}$ angle from wall (or nearest soft location) for approximately $50 \mathrm{~m}$ (or as far as the machine is capable). The target here is to create a herringbone-like surface drain directed to the low point in the dam (decant or similar in-board low point). This track will result in an approximate $35 \mathrm{~m}$ perpendicular distance from the wall.

Reverse along same scroll path all the way to the start (it is very important to stay in the same scroll track to maximise the effect). This is to be repeated along the wall approximately $1 \times$ scroll width apart (approximately $4 \mathrm{~m}$ apart).

The excavator should track the movement of the MudMaster to ensure the tethering line remains under tension but not under load to retain directional control.

When the MudMaster scrolling has been completed the excavator is to be tracked across the wall or internal header road and to ensure that unimpeded drainage occurs along scroll lines (the wall end will become disturbed due to MudMaster changing direction). The excavator will not need to venture beyond the header road as all work will be very close to the wall.

\section{Step 2 - Day 3}

For the next cycle, this process is to be repeated along the same scroll lines to deepen the scroll tracks and accentuate the surface drainage development. Excavator involvement will be required as before to preserve drainage.

\section{Step 3 - Day 5}

For the next cycle, the MudMaster must split the previous scroll tracks and the whole process is repeated with excavator support.

\section{Step $4-$ Day 7}

Re-scroll the previous scroll-lines as before with excavator support.

After four scrolls $(2 \times$ in each scroll line) progress monitoring is required. Every 12 scroll tracks (a lateral distance of approximately $100 \mathrm{~m}$ the MudMaster should stop approximately midway (of the maximum tracking distance) and a shear vane measurement taken (this will be at a 1 and $2 \mathrm{~m}$ depth shown as $1 \mathrm{~S}$ and 1D, etc.). Time, date and approximate location are also to be recorded.

The rate of change of shear strength will be recorded and the process adjusted accordingly. If shear strength development is not readily achieved additional excavation and drying actions may be considered. 
Photographs are also required from fixed points on the wall to monitor progress and match with shear vane data.

The process is then to be repeated until the target density or shear strength of the residue is achieved, from Step 1, and additional data recorded.

As tailings dewaters higher stress will be transmitted to the bearings on the MudMaster scrolls. To avoid undue stress or potential bearing failure, minor tailings pours may be placed $(100 \mathrm{~mm})$ as required to create scroll slippage.

As density improves and the scroll lines stay open the repeat scrolling can be eliminated and alternate scrolling and splitting can occur.

If necessary, as strength permits, the length of scroll lines can be extended to increase the width of the foundation footprint.

\subsection{Geotechnical investigation and monitoring}

The primary goal of the programme is to develop sufficient shear strength over the foundation zone footprint to satisfy geotechnical design requirements. The geotechnical investigation programme is critical to assessing the limitations of this (and other) approaches, and to define the viability of upstream raise options.

The geotechnical investigation and monitoring programme requires the following stages:

- Initial subsurface investigation (including CPTu's and vane shear testing).

- Ongoing vane shear testing during improvement works.

- Tailings surface survey.

- Visual monitoring.

\subsubsection{Initial subsurface investigation}

Initial investigation of the upstream footprint is required to assess stratigraphy, depth and consistency of existing tailings. Experience has shown that tailings can comprise layers of variable consistency, depending on historical tailings placement methods/campaigns. These layers of variable consistency are critical when carrying out detailed slope stability and settlement analyses. The tailings deposit typically includes mildly cemented (i.e. dense/hard) layers as well as soft poorly-consolidated layers. It is also critical to identify and consider the presence and continuity of any possible drainage layers (i.e. more permeable zones) within the deposit. Zones of higher permeability are usually the result of segregated deposition that has occurred historically due to unplanned/uncontrolled changes in mud rheology due to process difficulties.

Access onto the existing tailings (to carry out geotechnical investigation) is normally not possible due to the extremely low ground pressure of the upper tailings.

Modifications are possible to standard MudMaster equipment to carry out cone penetrometer testing with piezocone $(\mathrm{CPTu})$ and accurate vane shear testing (in accordance with Australian Standards AS1289-6.2.1 requiring Vanes to be rotated at a rate of $6^{\circ}$ per minute). To ascertain a three-dimensional (12D) model of the existing tailings surface, natural ground surface, phreatic surface and 'layers of interest', a grid of CPTu's over the upstream footprint plus at least $20 \mathrm{~m}$ outside the proposed footprint) is recommended.

\subsubsection{Vane shear monitoring}

The use of handheld shear vane shear equipment is a common 'indicator' tool to determine shear strength in tailings when used in accordance with AS1289-6.2.1.

A key tool used to monitor ongoing ground improvement performance is the correlation between $\%$ solids $\mathrm{w} / \mathrm{w}$ and vane shear strength. This investigation requires parallel residue sampling of $\%$ solids and vane shear strength. The \% solids is determined using a drying oven (as per Australian Standards) and vane shear as per the methods used in this investigation. At similar operations this investigation requires a minimum of 30 parallel samples over a range of moisture contents and may require up to 200 to develop a robust, site specific correlation. For bauxite residue this correlation becomes evident above approximately $60 \%$ solids 
$(\mathrm{w} / \mathrm{w})$ for Australian bauxites. Therefore it is possible to infer a $\%$ solids based on vane shear strength and vice versa with some confidence.

Due to the relationship between \%solids and vane shear for bauxite residue (verified with many different types of bauxite residue) large changes in density below approximately $60 \%$ solids show up as very minor changes in vane shear strength. It is only when the density increases above $60 \%$ solids that the large changes in vane shear strength occur. Figure 3 shows this generalised relationship.

\section{RATE OF STRENGTH INCREASE}

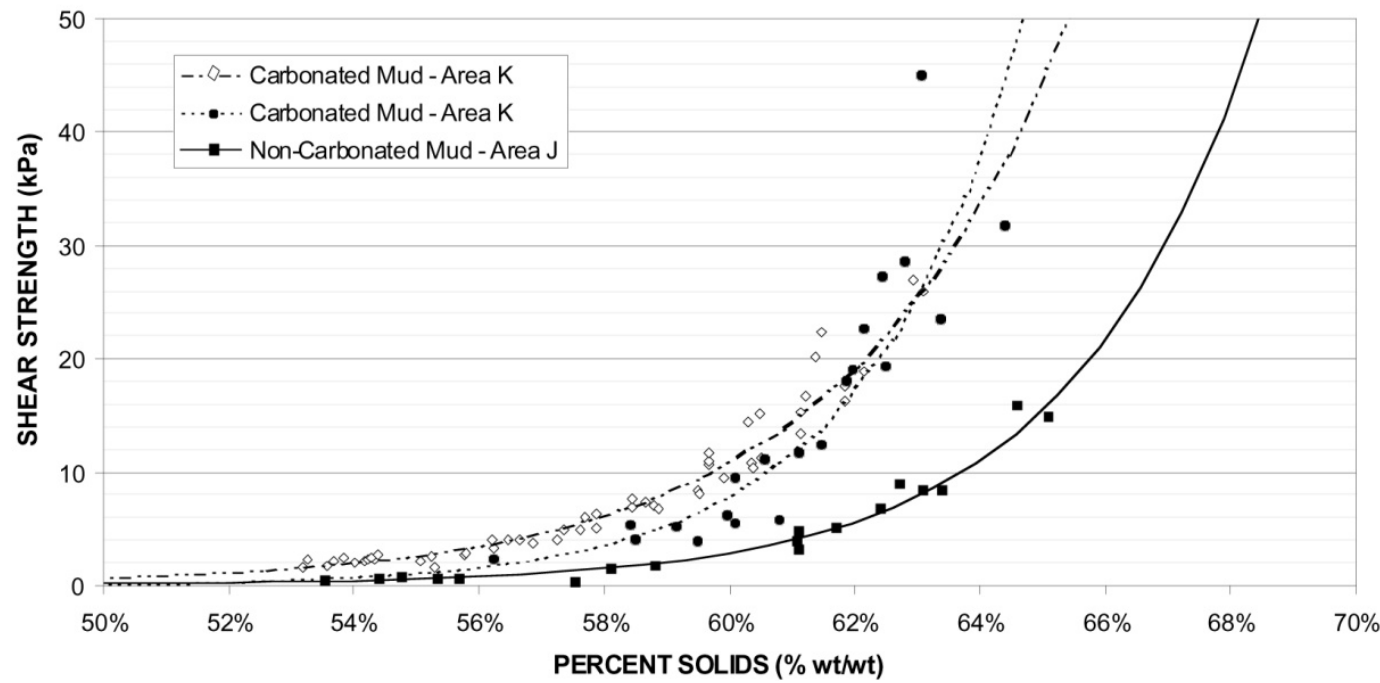

Figure 3 Strength increase as a function of density for carbonated and non-carbonated bauxite residue slurries (Cooling et al., 2002)

\subsubsection{Tailings surface survey}

As the tailings dewater they will consolidate. Routine weekly survey of shoreline tailings elevation at fixed locations provides a guide as to the rate of dewatering. These data can be used to compare progress against the modelled prediction.

\subsubsection{Visual monitoring}

While it may seem elementary, dewatering tailings provide distinct visual cues to the relative progress of the dewatering efforts. This is of particular importance during the initial dewatering stages before any significant vane shear strength has developed. As a general rule, if a tailings layer is not draining it is not drying. Therefore, the presence of pooled liquor on the surface is evidence of poor drainage and should be removed either by temporary pumping or alignment of the surface drains using the MudMaster.

Prior to any construction the $\mathrm{CPTu}$ investigation is repeated to confirm foundation suitability for construction.

\section{Results}

Variations to the intended foundation improvement plan can be broadly categorised as follows:

- Impacts due to rainfall - Logically, if it is raining in excess of modelled average values, this suppresses the evaporation rate. As most fine tailings exhibit hysteresis with respect to the absorption of rainfall this impact tends to be limited to the lost opportunity of net evaporative loss provided that surface drainage can be maintained.

- Intensity of operation - To reduce the total time required to complete the programme it is assumed that seven day operation can be maintained by the site. This is not always possible due to external influences. The impact is that the rate of dewatering is slowed and the likely completion time extended. This can be partially compensated by providing additional equipment (MudMasters) for 
the duration of the project but the net effect is to increase overall cost yet still have a below target dewatering rate.

- Water level in adjacent decant areas - The rate of dewatering is implicitly linked with the water level of any adjacent decantation areas. As the tailings are dewatered they will consolidate and the relative levels reduce in accordance with expectations. However, as the level reduces if there is not a commensurate reduction in the decant level the effectiveness of drainage from the foundation tailings layer will reduce and the rate of overall dewatering will decrease. Generally, the critical requirement is to maintain a $2 \mathrm{~m}$ differential between the tailings level and the decant water level.

- Monitoring variability - Inherent in the use of handheld vane shear is the variability in data due to the techniques and used personnel used (i.e. it is noted that hand held vane shear testing in accordance with AS 1289-6.2.1 is very difficult to achieve and results can vary depending on the rate at which the vane is rotated). As such the data gathered is considered to be an indicator and is relevant when expressed as a trend of strength gain.

- Spatial variability - As a MudMaster ploughs an area it creates a deeply contoured surface. Therefore, there is variance in spatial tailings density and density changes in depth.

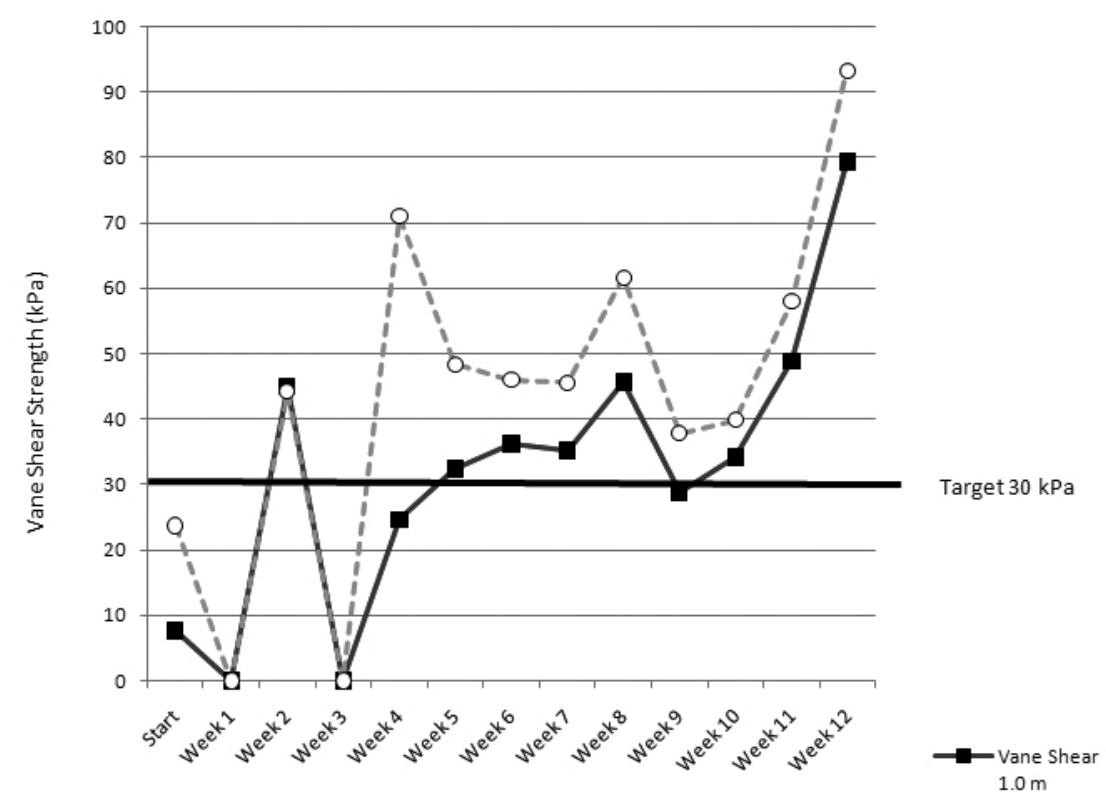

Figure 4 Vane shear strength change of non-carbonated bauxite residue with time

Data was recorded every $100 \mathrm{~m}$ at 1.0 (shallow) and $2.0 \mathrm{~m}$ (deep) and recorded weekly. The foundation improvement area measured approximately 900 by $40 \mathrm{~m}$ and was managed by using one MudMaster. The generalised progression of strength improvement in accordance with the programme (and averaged over the entire length of the study area) is shown in Figure 4.

From Figure 4 the vane shear data clearly shows a progression from a $<25 \mathrm{kPa}$ range to $>80 \mathrm{kPa}$ range. While the changes in these strengths are significant the commensurate change in density is minimal. Visually such changes are very difficult to detect.

As was seen in the data, initial changes in vane shear strength were minor or at least hidden by variability. However over time, as would be expected in a dewatering residue, a trend is emerging showing increasing strength and hence increasing density.

Early in the programme it was identified that the vane shear testing was highly variable and very dependent on the actual location of the test. This was unavoidable due to the nature of the scrolling action. It is during this period that key reference to the visual and survey data can continue to indicate dewatering progress in the absence of reliable vane shear data. The presence of intermediate peaks was assessed in this way. It was the development of the trend and the variability in the trend that was more important than the peaks. 
Specifically once the trend became firmly developed (after Week 10) the relative variability reduced. In addition the visual changes to the residue and the survey data of the relative levels (not shown) indicated the overall stabilisation of the foundation area and an increase in density and strength. While using a vane shear can provide useful data, it is limited at the lower densities and therefore a good understanding of the initial residue conditions and dewatering behaviour is critical for it to be useful. After the completion of the programme, a repeat of $\mathrm{CPTu}$ testing ( 2 weeks after the completion) confirmed the broad development of strength $(>30 \mathrm{kPa})$ in all areas of the foundation area.

The key focus of this paper is to develop cost-effective tools to support construction needs that can be readily utilised whilst using detailed inspection methods to confirm these results.

The changes shown in Figure 4 were produced for a total effective cost of A $\$ 422,000$ (inclusive of equipment, operations, personnel and monitoring) with this cost absorbed within an existing operating budget. This expenditure eliminated the need to provide for over A\$1,500,000 of capital works and was completed within the original timeframe.

\section{Conclusions}

Ground improvement via dewatering methods can provide significant savings in the order of $A \$ 1,000,000$ for a moderate upstream raising foundation improvement programme.

Such works should only be considered with a geotechnical engineering programme that includes investigation, design and monitoring.

Ground improvement using in situ dewatering equipment (MudMasters) has been successful for the preparation of foundations for upstream raising of embankment walls. This method does rely heavily on climatic conditions and requires a detailed 'daily time step' plan to maximise drying rates during drier months. Evaluating this progress daily using a range of different and inexpensive techniques allows operational activities to be tailored to suit the conditions.

The provision of additional equipment does not always means increased dewatering/drying rates and requires ongoing supervision/monitoring to avoid "repulping" dried tailings. It is by maximising the value from the necessary equipment that will result in the greatest benefits. The mud farming plan includes dewatering patterns and frequency rates to specifically suit site conditions and tailings composition and rheology.

It is suggested that when considering ground improvement of tailings for upstream construction that the owner provides sufficient contingency for conventional 'bridging layers' in areas where greater than $8 \mathrm{~m}$ of consistently very soft tailings exist (i.e. without any harder/dense layers throughout). Conventional bridging layers may include the use of rock fill/high strength geotextiles/geogrids. It is noted that before these methods are adopted, a deep recovery/dewatering method could be tried (and modified accordingly to suit site conditions) using available MudMaster equipment. It is only when negligible strength gain is observed that the alternative methods would be adopted.

This process has been successfully used at several sites.

\section{Acknowledgements}

The authors acknowledge the assistance provided by Residue Solutions Pty Ltd in preparing the MUDFARM ${ }^{\mathrm{TM}}$ modelling that underpinned the improvement programmes mentioned in this paper and also guidance with respect to efficient MudMaster operation.

The authors also acknowledge the assistance provided by CPTS Pty Ltd regarding assistance in modifying the MudMaster to accommodate the CPT testing equipment.

\section{References}

Cooling, D.J. (2006) Improving the Sustainability of Residue Management Practices - Alcoa World Alumina Australia, in Proceedings Tenth International Seminar on Paste and Thickened Tailings (Paste07), A.B. Fourie and R. Jewell (eds), 13-15 March 2007, Perth, Australia, Australian Centre for Geomechanics, Perth, pp. 3-16. 
Cooling, D.J., Hay, P.S. and Guilfoyle, L. (2002) Carbonation of Bauxite Residue, in Proceedings 6th International Alumina Quality Workshop, 8-13 September, 2002, Brisbane, Australia, pp. 185-190.

Power, G., Gräfe, M. and Klauber, C. (2009) Review of Current Bauxite Residue Management, Disposal and Storage: Practices, Engineering and Science, CSIRO National Research Flagships - Light Metals, DMR-3608, May 2009. 